\title{
Configurações da percepção contemporânea e metaformas na televisão: estudo de formas visuais da MTV Brasil
}

\section{RESUMO}

O Partindo do viés do campo de estudo das materialidades, nosso trabalho realiza uma reflexão sobre o modo como as tecnologias eletrônicas de comunicação configuram novas formas de percepção da realidade e de interação coletiva. É sob este prisma que, ao estudar programas da MTV Brasil, buscamos encontrar em suas imagens, percepções do mundo contemporâneo derivadas do acoplamento do sistema central de seus jovens telespectadores com as novas tecnologias de comunicação, considerando que as percepções advindas deste acoplamento são de vital importância para a configuração das mensagens, interferindo diretamente nas decisões de formatação dos programas por parte da emissora.

\section{PALAVRAS-CHAVE}

- televisão

- tecnologias de comunicação

- percepções contemporâneas

\section{ABSTRACT}

Through this work, and starting from field bias of the materiality study, we reflect on how the electronic communication technologies create new ways of perceiving reality and collective interaction. Under such prism, studying MTV Brasil's programme images in Brazil, we have tried to find perceptions of the contemporary world derived from the coupling of its young viewers' central system with the new communication technologies, taking into consideration the fact that the perceptions that arises from such couplings are of vital importance for the configuration of messages, and directly interfere on the formatting of the programs by the broadcasting company.

\section{KEY WORDS}

- television

- communication technologies

- contemporaneous perceptions

\section{Silvia Cristina Jardim e Solange Wajnman UNIP}

$\mathbf{N}$ este trabalho buscamos investigar a maneira como as mudanças de percepção trazidas pelas tecnologias eletrônicas da televisão, do computador e da internet estão sendo configuradas nas imagens das emissoras de televisão segmentadas. Para tanto, escolhemos analisar a programação da MTV Brasil, joint-venture entre a Abril S.A. e a MTV Networks, pertencente ao mega grupo multinacional de entretenimento Viacon Inc, destinada, sobretudo aos jovens.

Os jovens hoje representam o segmento da população que possui o melhor domínio sobre as tecnologias de comunicação. Desde muito cedo eles convivem com o ambiente multimídia, utilizando-se dele para jogar, brincar, aprender e, principalmente, para se comunicar e formar relacionamentos. Se estes jovens, hábeis usuários das tecnologias eletrônicas de comunicação, são o público da MTV Brasil, devemos supor que as imagens e os formatos de seus programas estejam sendo desenvolvidos de acordo com estas percepções, valores, estilos e ideologias.

As imagens da MTV são distribuídas no mundo todo, disseminando aquilo que ficou conhecido como "estilo MTV", sinônimo de ousadia e juventude. Equipamentos de última geração, técnica de edição de videoclipe, linguagem coloquial e visual computadorizado, entre outras coisas, são utilizados de maneira a conquistar o público jovem. Isto acontece porque a MTV Networks utiliza o sistema de franquias para poder estar nos mais diversos recantos do mundo. Enquanto licenciadora vende sua marca e produtos e presta atendimento às franqueadas em troca do pagamento de royalties. Suas afiliadas operam segundo a filosofia da matriz americana: "Thinks Globally, Acts Locally". Baseadas neste princípio, todas elas aderem ao estilo visual e ao formato da rede, promovendo seus produtos, sem contudo descartar a cultura musical local (Lusvargh, 2002: 21). Este procedimento reflete a globalização da cultura jovem nascida na década de 50 e, hoje, disseminada de maneira simultânea, graças à velocidade de transmissão das tecnologias de comunicação. Os jovens dos mais diversos países que assistem à MTV cultuam as mesmas grifes de roupa e os mesmos ídolos, ouvem as mesmas músicas, consomem os mesmos produtos e interagem de maneira semelhante com as tecnologias de comunicação, sem abdicar dos costumes de seus países de origem $^{1}$. São estes jovens, espalhados pelo mundo, com suas percepções de realidade, que irão participar ativamente da construção de uma linguagem multimídia e da disseminação de novos hábitos, costumes e maneiras de se relacionar com os outros e 
com o mundo. Nos últimos anos assistimos à fusão de várias empresas de comunicação, sendo o aparecimento do computador, da linguagem digital e da comunicação via internet aspectos fundamentais da revolução que vem ocorrendo neste setor. Todos os dias surgem notícias de alianças estratégicas entre empresas que estão em busca de novas formas de linguagem que compactuem com as tecnologias eletrônicas e as novas formas de comunicar e interagir do homem contemporâneo. Não é diferente com a Viacon Inc., que está em terceiro lugar no ranking de faturamento das grandes empresas multimídias do mundo, atrás da AOL-Time Warner e da Disney Company (Castells, 1999: 427). Fazem parte da Viacon Inc. canais de TV aberta e a cabo, a editora Simom E Schuster; as locadoras Blockbuster, empresas da indústria cinematográfica como a Paramount Pictures e outras empresas de internet, parques temáticos, outdoors e redes de rádio (Lusvargh, 2002: 17-18).

Este panorama empresarial aponta para o surgimento de um mercado multimídia, definido por Castells (1999: 450-455) como um novo sistema de comunicação eletrônico, que nasce a partir da fusão da mídia de massa personalizada e globalizada com a comunicação mediada pelos computadores. A principal característica deste sistema é a integração dos vários meios de comunicação com os seus potenciais interativos. Este autor ainda aponta o fato de que as transformações tecnológicas estão evoluindo num ritmo mais rápido do que a evolução de transmissão das mensagens, pois, embora as grandes empresas de comunicação estejam fazendo grandes esforços no sentido de encontrarem conteúdos e mensagens adequadas ao novo meio, os caminhos ainda são muito incertos.

Para Montez e Becker (2005: 34), podemos definir de maneira simplificada a transmissão televisiva como o fruto de um conjunto de procedimentos tecnológicos que incluem a produção, edição, transmissão e recepção, através dos quais o sinal da TV chega até a casa dos telespectadores. Hoje, no Brasil, as maiores operadoras possuem metade dos estúdios de geração já digitalizada, convertendo o sinal digital em analógico no momento da transmissão e ainda não podemos dizer ao certo qual o resultado da completa digitalização do sistema de transmissão televisivo. Para os referidos autores o surgimento de uma TV digital interativa "não é uma simples junção ou convergência da internet com a TV, nem a evolução de nenhuma das duas, é uma nova mídia que engloba ferramentas de várias outras, entre elas a televisão como a conhecemos hoje e a navegabilidade da internet."(2005: 58).

Considerando estes movimentos tecnológicos, econômicos e socais, escolhemos estudar a MTV Brasil buscando encontrar em suas imagens, percepções do mundo contemporâneo derivadas do acoplamento do sistema nervoso central de seus jovens telespectadores com as novas tecnologias de comunicação, considerando que as percepções advindas deste acoplamento são de vital importância para a configuração das mensagens, interferindo diretamente nas decisões de formatação dos programas por parte da emissora.

\section{Considerações sobre o campo epistemológico}

A concepção geral que ancora este trabalho está ligada à questão da materialidade e sob o ponto de vista do campo não-hermenêutico. Dentro deste campo, grandes pensadores como George Simmel, Siegfried Kracauer, Walter Benjamim, Marshall McLuhan e, mais recentemente, Hans Ulrich Gumbrecht defendem a visão de que tão importante quanto os sentidos e significados (campo de estudo da hermenêutica) são os efeitos que as tecnologias causam em nossos corpos e como estas modificações acabam influenciando e participando como co-agentes da transformação da própria cultura.

Na sociedade contemporânea, as Ciências Sociais estão passando por um período que remete ao declínio de determinadas certezas do mundo filosófico ocidental. Gumbrecht (1998), em seu texto "Corpo e Forma", nos ensina que neste mundo, o homem é entendido como o centro da geração e recepção de sentidos - visão hermenêutica onde tradicionalmente se colocam os estudos de comunicação. Nesta visão hermenêutica, os objetos exercem apenas a função de doadores de um sentido espiritual maior e a cultura pertence a um território dominado pelo simbólico e imaterial (Felinto e Andrade, 1994: 77). O campo nãohermenêutico, proposto por Gumbrecht, está preocupado com a problematização do ato interpretativo, levantando a questão das materialidades, na qual os objetos assumem suas especificidades materiais e participam ativamente na construção do tecido cultural, relacionando-se com o corpo humano antes mesmo da formação destes sentidos.

Para apresentar o campo não-hermenêutico, Gumbrecht parte da teoria da semiótica de Louis Trolle Hjelmslev ${ }^{2}$ onde a oposição conceitual básica relaciona "expressão x conteúdo". Esta relação inicial pode ser desdobrada em quatro campos: a "forma da expressão" 3 e a "forma do conteúdo" ${ }^{4}$, na qual se situa o modelo de signo de Saussure; e a "substância da expressão" 5 e a "substância do conteúdo"6.

Hjelmslev estava preocupado com a síntese destes quatro elementos. Gumbrecht, ao contrário, está preocupado com a crescente tendência contemporânea de distensão e distanciamento destes quatro elementos em campos separados de estudo, ou seja, com a possibilidade de tematizar o significante (objeto) sem necessariamente associá-lo ao significado (interpretação).

A intenção de Gumbrecht é buscar compreender a passagem da "substância da expressão" para a "forma da expressão", preocupando-se inclusive com a possibilidade expressiva do corpo humano enquanto meio de articulação. Isto significa dizer que nos preocuparemos em entender como as infinitas possibilidades de uso de determinada materialidade pelo homem podem resultar na articulação de um determinado tipo de forma. Dentro deste ponto de 
vista podemos pensar, por exemplo, sobre como a partir da ilimitada diversidade potencial de possibilidades físicas da voz, formularam-se códigos articulados que resultaram nas línguas, tal qual as conhecemos hoje. Como, a partir de milhares e milhares de possibilidades de combinação do código binário dos computadores podem resultar sistemas escritos ou audiovisuais de comunicação.

Gumbrecht vai utilizar o conceito de acoplagens da teoria dos sistemas biológicos ${ }^{7}$ para buscar entender como a materialidade dos objetos, associados às possibilidades do corpo humano, podem ser combinados de maneira a resultar em diferentes formas previamente desconhecidas, já que o número de combinações pode ser infinito. ${ }^{8}$

Deste modo, a linha de pensamento das materialidades pressupõe que sob a influência dos objetos nossos corpos estão em permanente evolução de acordo com os estímulos que recebem, proporcionando a emergência constate de novos sentidos e outras maneiras de perceber e interagir. Como explicam Felinto e Andrade (1994: 79), dentro deste contexto "a cultura se caracteriza como uma realidade constituída por objetos e acoplagens entre sistemas (por exemplo, o sistema 'humano' e os sistemas tecnológicos)".

Isto significa que buscamos entender, a partir das análises das imagens da MTV Brasil, como as tecnologias eletrônicas e digitais de comunicação estão afetando os corpos, percepções e sensações de seus jovens espectadores, antes mesmo da formação de qualquer sentido, e como este acoplamento entre seus corpos e estas tecnologias está contribuindo para a construção da cultura contemporânea e de outras formas de mensagens. Durante este trabalho nos apoiamos sempre em dois tipos de acoplagens de sistemas, o corpo humano e a tecnologia eletrônica da televisão e o corpo humano e a tecnologia digital do computador, para então poder traçar relações entres as percepções resultantes de cada acoplamento.

O método de trabalho se concentrou em entender as tecnologias da televisão e do computador e seu funcionamento buscando pontos em comum, metáforas (como a de "navegação" pelo ambiente televisivo) e correspondências (entre a formatação dos programas da televisão e a navegação pelo espaço informação do computador ou nas linguagens das duas tecnologias) através de uma leitura transversal, conforme propõe Maffesoli (1998, p. 146).

Isto significa que se buscará, através destas analogias, correspondências, metáforas, colagens e aproximações sucessivas, estabelecer conexões entre as percepções derivadas do uso da tecnologia do computador e a formatação dos programas da MTV Brasil.

\section{Considerações sobre percepções e imagens videográficas}

A disseminação da tecnologia da televisão aconteceu por volta dos anos 50. De início, McLuhan (1974: 351353) definiu suas imagens como um borrão formado por um fluxo de raios catódicos que bombardeavam o espectador com uma explosão de estímulos sensoriais. Segundo o autor, para decodificar essas imagens o telespectador tinha que usar seu raciocínio para completar as formas e fazer com que elas fizessem um sentido, usando para isso as Leis da Gestalt ${ }^{9}$. Esta dinâmica exigia uma participação convulsiva e sensorial que era profundamente cinética e tátil, tornando a televisão uma extensão do nosso sistema nervoso central.

Para McLuhan a tecnologia da televisão foi o marco do entendimento e superação das percepções das sociedades letradas que predominou no mundo ocidental por muitos séculos. Enquanto as tecnologias mecânicas advindas da imprensa e da Revolução Industrial nos fornecem uma percepção recortada e serializada, as tecnologias da eletricidade trazem percepções ligadas à simultaneidade e à configuração. As linhas de produção da Revolução Industrial são lineares, dividem o processo de fabricação em várias etapas e especializam o trabalhador, que conhecendo somente uma parte da produção perde a visão do todo. As tecnologias eletrônicas, por sua vez, são baseadas no circuito onde as conseqüências de qualquer ação acontecem ao mesmo tempo, de forma simultânea, requisitando a retro-alimentação e o envolvimento.

O meio de comunicação que caracteriza a sociedade mecanicista é a imprensa. O ato de leitura através da utilização do código da escrita requer o uso de apenas um dos sentidos para a sua compreensão: a visão. Através deste instrumento de comunicação temos uma percepção recortada, ou seja, só conseguimos perceber uma parte do todo, já que usamos somente um dos sentidos, deixando de lado os outros. Isto explica porque as sociedades pautadas na imprensa podem ser caracterizadas por um modo antropocêntrico de ver o mundo. Elas somente percebem a si próprias e consideram de menor valor todo conhecimento das sociedades orais.

A sociedade contemporânea, no entanto, tem como meio de comunicação mais influente a televisão, e o ato de assisti-la exige que utilizemos simultaneamente vários outros sentidos além da visão, implicando na nossa participação e envolvimento. McLuhan (2003:105) chamou de "participação em profundidade" ${ }^{10}$ esta participação sinestésica que requer envolvimento e comprometimento para o preenchimento de dados e re-configuração do sentido da mensagem, percepção advinda das tecnologias baseadas no circuito e na retro-alimentação.

Hoje, as imagens da televisão são de alta definição e não precisamos mais completar seus sentidos através das Leis da Gestalt. A participação em profundidade acontece em outros níveis, como observam Natário e Wajnman (2006:15), na imersão em menus e personalização de programas nas TVs a cabo ou por satélite e, como buscaremos demonstrar neste trabalho, na participação cada vez mais ativa por parte dos telespectadores na construção das mensagens. 
Além disso, não podemos perder de vista que agora a produção e edição das imagens da televisão são quase na sua totalidade feitas em formato digital e transformadas em formato analógico somente no momento da transmissão. Assim podemos dizer que esta modificação dos níveis de participação em profundidade foi uma conseqüência do acoplamento dos nossos sentidos às imagens videográficas do computador e da combinação destas imagens com as imagens da televisão.

O computador digital processa informações através de minúsculos pulsos de eletricidade que representam os estados "ligado" e "desligado", ou 0 e 1. Como explica Johnson (2001:17), no início a linguagem do computador era simplesmente uma mistura de combinações destes códigos binários e comandos abreviados. Atualmente a imagem videográfica do computador é gerada através de um mapeamento de bits, cada pixel na tela do computador remete a um pedaço de sua memória, cada bit é referente a um dígito que pode estar aceso ou apagado.

É importante ressaltar que a imagem da tela do computador tem muitos pontos em comum com a tela da televisão. Ambas são imagens construídas através de circuitos - sejam eles digitais ou analógicos - e ambas podem ser consideradas imagens estilhaçadas ou em forma de mosaico, pois se tornam visíveis aos nossos olhos através da composição de pontos que estão acesos e pontos apagados.

A principal e fundamental diferença entre o computador e a televisão é que o computador é um sistema de comunicação que inclui a auto-representação, o que agilizou e potencializou a construção de imagens sintéticas. O computador está muito mais preocupado em facilitar ao usuário a navegação pelas suas informações do que em representar o real (Johnson, 2001:18). A invenção do mouse permitiu que manipulássemos estas informações de maneira direta, ele representa nosso "duplo-virtual", nosso representante no espaço-informação, dando a sensação de que podemos entrar e participar destes mundos virtuais (2001: 22). E é neste ponto que as imagens videográficas trouxeram ao mundo contemporâneo um novo tipo de percepção, que veio somar-se às percepções da televisão.

Com o computador continuamos a utilizar todos os nossos sentidos para a apreensão da mensagem. Sons, imagens, textos escritos, conceitos; um fluxo de imagens em forma de mosaico operando em nosso sistema nervoso e desafiando nosso pensamento a operar e interagir em condições de atualidade, levando-nos à participação em profundidade. Tanto o mouse do computador como o controle remoto da televisão funcionam como extensões do nosso sistema nervoso central, através deles podemos entrar em mundos virtuais e realmente interagir, participar, manipular e modificar as coisas. Isto mudou não somente o modo como usamos nossas máquinas, mas também o modo como pensamos sobre elas. Agora as máquinas não são mais simplesmente extensões do nosso corpo ou dos nossos sentidos, mas representam um ambiente, um espaço a ser explorado através do acoplamento destes sentidos (Johnson, 2001: 23).

Estas imagens videográficas - que hoje compõem as imagens da televisão, dos computadores, dos videogames e dos celulares, entre outras - são imagens fluxo, elaboradas através de feixes de elétrons e fazem parte da paisagem do nosso cotidiano. Assim as mudanças de percepção trazidas primeiro pela televisão e depois pelo computador não ficaram isoladas, mas se inseriram no mundo contemporâneo, permitindo que atuemos não só num "ambiente televisivo", mas que migremos agora para outro ambiente, um "ambiente virtual" de informações e imagens sintéticas.

\section{Percepções contemporâneas e formatos na programação da MTV}

Desde o seu surgimento, a televisão apoderou-se dos vários textos e imagens que já faziam parte do nosso repertório cultural. Para Balogh (2002: 23), "a televisão é o resultado de um complexo processo de evolução e entrelaçamentos entre os campos da tecnologia, das comunicações e das artes". Segundo a autora, aquilo que podemos chamar de linguagem da televisão é uma mistura de tudo o que foi desenvolvido anteriormente pelo rádio, cinema, artes plásticas, fotografia, literatura. Todas estas influências, e mais outras, foram absorvidas de maneira assimétrica, deglutidas, transformadas e somadas a novas propostas, como a linguagem publicitária, do videoclipe e da computação gráfica.

Dentre as influências mais aparentes, podemos citar que o mais simples programa de televisão traz consigo arranjos de som e imagens herdados do cinema. As noções de enquadramentos são derivadas das artes plásticas e da fotografia, os ganchos utilizados entre os intervalos de programação remetem ao folhetim literário e radiofônico (Balogh, 2002: 24) e, mais recentemente, as vinhetas de apresentação dos programas e os spots de identidade vêm da computação gráfica.

Podemos dizer que a linguagem da televisão ainda está em processo de construção, pois ela se apodera e se transforma toda vez que uma nova tecnologia ou nova expressão aparecem. Além disso, por estar disponível 24 horas por dia, nos sete dias da semana, ano após ano, a televisão precisa de muito conteúdo para preencher todo este tempo de programação, por isso ela devora, reforma, reapresenta e descarta inúmeros programas de maneira insaciável (Balogh, 2002: 25).

Como conseqüência desta característica, a televisão já está absorvendo as percepções do computador e da internet, através daquilo que Johnson (2001: 2435) chamou de metaformas ou metaprogramas. Estes formatos de programas estão interessados em "navegar" por ambientes informacionais, como aqueles criados pelos computadores. Eles comentam, desmantelam, dissecam, sampleiam todo tipo de informação que está disponível nos vários meios de comunicação 
do mundo contemporâneo, sendo que uma de suas características fundamentais é que eles trazem embutidas percepções que estão além de seu tempo, esperando o aparecimento de um novo meio que possa satisfazê-las de forma plena.

A televisão e o computador são tecnologias da eletricidade e suas imagens videográficas estão presentes em nosso cotidiano por onde quer que se vá, propagando-se e contaminando outros meios em alta velocidade. Os navegadores são necessários para nos guiar por esta avalanche de imagens e informações. $\mathrm{O}$ telespectador hoje quer "entrar" no mundo da televisão, como faz com o mundo virtual. Ele quer interagir, participar, dar opiniões, concordar ou discordar, ajudar a construir as mensagens de acordo com suas percepções contemporâneas, adquiridas com o uso das tecnologias eletrônicas e digitais. Mas a tecnologia da televisão, apesar do controle remoto, ainda não consegue oferecer uma interatividade compatível à do mouse.

A programação da MTV, por si só, já representa um mergulho no universo da música jovem. A grande maioria de seus programas é criada para falar deste universo, seja em formato de jornalismo, como o "Jornal MTV", seja em forma de programas de variedades, como o "Chapa Coco" ou o "Disk MTV". A MTV foi uma das primeiras emissoras a utilizar as metaformas descritas por Johnson com a criação de "Beaves $\mathcal{E}$ Butt-head". Neste programa, dois amigos "canastrões" navegavam com muita ironia pelos videoclipes, realizando o desejo de participação e interatividade dos telespectadores. Já nos anos 90, "Beaves \& Butt-head" eram o duplo-virtual do telespectador; viam e ouviam, opinavam e ajudavam a construir a mensagem.

Dentro do período analisado neste trabalho ${ }^{11}$, podemos identificar na grade da MTV alguns programas em especial que traduzem de maneira mais elaborada esta necessidade de navegar pelas informações, interagir e participar da construção das mensagens.

O programa "Top Top" traz toda semana uma lista dos "10 mais" do mundo do rock; os 10 astros mais ricos, os 10 "foras" mais surpreendentes, os 10 estilos de cabelo mais notáveis, os 10 fãs clubes mais chatos, os 10 vocalistas mais desafinados e assim por diante. Para cada um dos programas, apresentados por Leo Madeira e Marina Person, são escolhidos cenários de acordo com o assunto abordado. Em “Piores Vocalistas", quando foram escolhidos os 10 vocalistas mais desafinados, o cenário foi um luxuoso banheiro, com banheira de hidromassagem, espuma e pias de mármore, insinuando que os vocalistas desafinados deveriam limitar-se a cantar em seus próprios banheiros. Apresentados em ordem decrescente, cada integrante da lista passa por uma análise bem humorada dos apresentadores, que explicam o porquê da classificação em off, enquanto vemos imagens recortadas de vários clipes, apresentações ao vivo, ou outras imagens de arquivo do artista e sua banda. É como se nos conectássemos ao Google e solicitássemos uma pesquisa "rock* vocalistas*desafinados". A diferença é que a seleção dos "10 mais", dentre as possibilidades resultantes de tal pesquisa, é feita pela equipe de produção e não pelo próprio espectador ou usuário, o que provoca muitas reclamações.

A versão 2006 para o "Cine MTV", também pode ser considerada uma metaforma. Dedicado a comentar os lançamentos dos filmes no cinema, nele os telespectadores podem participar por e-mail mandando listas com seus filmes prediletos comentados que são inseridos no programa em forma de frames. Podem também pedir clipes de músicas que são temas de filmes. Este programa representa uma navegação pelo universo do cinema e ainda permite o cruzamento das informações "música*cinema", realizado com a ajuda do telespectador e a utilização de mais um meio de comunicação, neste caso a internet.

O "Ya Dog" estreou na programação de 2006 com a vj também estreante Luiza Micheletti. "Ya Dog", além de ser o nome do programa é também o nome da mascote, um cachorro virtual em formato de "plug" que conversa com Luiza numa linguagem codificada que só ela consegue entender. Os dois juntos navegam, comentam e indicam conteúdos da internet: videos interessantes, músicas, notícias. A audiência pode participar enviando dicas que são compartilhadas, ou áudios e videos elaborados por eles mesmos, que são mostrados ao vivo.

Outro programa estreante foi o "Tribunal de Pequenas Causas Musicais" apresentado por Penélope Nova, que faz o papel de juíza, André Vasco, que representa a promotoria de acusação e Rafa Losso, o advogado de defesa. O júri é formado por três telespectadores que se inscrevem antes no site do programa. É no site também que a audiência faz as "denúncias" sobre o mundo da música. Toda semana questões como "O reinado de Britney Spears chegou ao fim?", "Está na hora da Madona pendurar o collant roxo?", "A música caipira é brega?" ou "O rock tá ficando gagá?" são levados ao júri. Durante o programa os advogados de defesa e acusação baseiam-se nas opiniões dos telespectadores, enviadas por e-mail, para construir seus argumentos; os jurados são ouvidos e por fim vem o veredicto, que é baseado nos números da enquete realizada no site.

Todos estes programas são derivações de "Beaves $\mathcal{E}$ Butt-head". Agora não é mais a dupla de amigos que navega dentro da programação da emissora, mas cada um dos telespectadores com a ajuda da internet. Cada um deles ouve, vê e opina, ajudando a construir as mensagens.

\section{"MTV de Bolso": a interação através da convergência dos meios}

Como dito acima, a linguagem digital que nasceu com o aparecimento do computador, é formada pelas múltiplas combinações possíveis entre os dígitos zero e um. Quanto mais esta linguagem avança, formando 
as imagens videográficas e contaminando não só a televisão como vários outros tipos de mídia, mais os equipamentos podem "conversar" entre si. Os jovens são os mais hábeis usuários destas possibilidades de entendimento entre os equipamentos, utilizando estas trocas de informação digital para criar formas de relacionamentos.

O programa "MTV de Bolso" é um grande chat na televisão, com todas as características de um batepapo da internet, no entanto, a interação é feita através da televisão, da internet e do celular. Para participar, antes é necessário efetuar um cadastro no site da MTV, criar um nick e mandar uma foto. Cada vez que o participante manda uma mensagem em formato digital pelo celular, seu texto é adicionado ao programa e transformado em formato analógico, deste modo sua foto e sua mensagem são transmitidos com o programa ao vivo. O nick e a foto servem para dar forma aos participantes dentro do ambiente do programa, personalizando seu duplo-virtual. O resultado desta interação é um grupo de indivíduos de vários pontos do país "falando" uns após os outros, num código abreviado e muitas vezes ininteligível.

Seguem abaixo alguns exemplos:

“Oi meu bebe to na MTV te adoro muito!!! Daiana de Alvorada" "Da pra passar o clipe novo do RED HOT CHILI PEPPERS, valew. Alexandra. $\mathrm{Rj}$. " “Bj pra galera de ribeirão preto via MTV! JOÃO PAULO” “Blz! To na mtv" "Qual eh mtv tok slipknot!bjaum p/ galera de Belém-PA e pro pessoal do $1 \mathrm{~b}$ impacto P.E. Falow Ayrton Carvalho." "DI = Da mtv comanda c/ bj po DIEGO e pa LEH. Viw i* by ana. CVA: PR toca nx zero :D" "Pow tm algum gatinhu precisandu di um amor? .!day!" "Lorrany te amooo 52 nao da pra viver sem voc. Rovagadom dia 30 no matriz ass: Rud tpn a lot" "Toca blink 182 pow o pgrama ta massa. Gabi t amo/fram PIK-RD/" "Aew galera da mtv! Um alow pa geral" i m bjo pa Aline ** ass: Lilizinha" "Hj estreia clipe d black eyed peace! To feliz! Bjs p/ galera do ojo! GABI RECIFE -PE" "Oi povo da MTV! Eu amo vcs. Passa a minha MSSI" "Adorei o MTV de bolso ta D +"

"Aew mtv toca um rap plzz. Pq faiz tempu q naum vejo clipe de rap na $\mathrm{mtv}$. Sei q naum tem muita gente q curte + pow. Oh tem amo. Abrcaum download. A" "Galera da MTV vocs sam 10. Bjos pra may, ani, wanda. Adoro vocs!!!” “To na mtv. Vivi."

Neste formato acontece um encontro do videoclipe com a sala de bate-papo da internet, viabilizado pela tecnologia de produção de imagens digital da televisão. Por três horas seguidas, tempo de duração do programa, assistimos ao fundo os videoclipes e, sobre esta imagem, abrem-se "subjanelas" onde se pode ler a participação da audiência.

As "janelas" são ferramentas de navegação formu- ladas para o ambiente do computador, criadas para que pudéssemos operacionalizar, de maneira simplificada, vários modos de operação desta máquina. Ao invés de digitarmos linhas de comando cada vez que precisássemos sair do modo texto para o modo gráfico, por exemplo, foram criadas interfaces que podiam ser acessadas de forma direta e utilizadas de maneira alternada. Isto permite que realizemos múltiplas tarefas no espaço-informação da tela. Com o passar do tempo, a tecnologia possibilitou que estas janelas fossem sobrepostas, através de subjanelas, chamadas de frames ou quadros. "Uma única janela pode conter vários quadros, cada um contemplando uma região diferente da infosfera." (Johnson, 1999: 69). No "MTV de Bolso", os participantes vêem o videoclipe na janela principal e um frame é utilizado para a participação no chat. Assim conseguem realizar duas tarefas ao mesmo tempo: ver o videoclipe e participar do chat. Aqui a interação do telespectador se dá ao vivo, mas ele ainda não pode escolher os videoclipes ou chamar um dos outros participantes para uma conversa reservada, como aconteceria se ele estivesse navegando na internet.

O acoplamento do corpo do telespectador acontece de duas maneiras diferentes: ele recebe uma mensagem pela televisão e pode participar da re-configuração desta mensagem através do celular. Como resultado destas acoplagens, podemos destacar as percepções de participação em profundidade levantadas no decorrer deste trabalho. O telespectador assiste aos videoclipes, "ouve" os outros participantes e contribui para a construção da mensagem enviando sua própria saudação ao vivo. Além disso, ele navega por este ambiente representado pelo seu duplo virtual personalizado, de acordo com as percepções adquiridas com a utilização cotidiana do computador e do mouse.

Este programa ainda é uma metaforma, pois revela percepções que estão além de seu tempo esperando a chegada de um novo meio que venha possibilitar a interatividade num sentido mais pleno. Além disso, sinaliza um ponto onde a linguagem da televisão se encontra e parece se misturar com a linguagem da internet, preparando-se para a chegada da TV digital interativa.

\section{"Vidalog": a estética do hipertexto na televisão}

Da mesma forma que o chat, o blog também representa uma maneira de interação no mundo virtual da internet. Enquanto no chat esta interação acontece on-line, no blog as participações são assíncronas, ou seja, os participantes não precisam estar juntos no mesmo momento, cada um interage de acordo com a sua disponibilidade. No blog a participação pode acontecer de maneira mais profunda, já que existe um tempo maior para a reflexão e construção das mensagens.

O Programa "Vidalog" é um blog na televisão. Seu conteúdo vem de um blog de mesmo nome que é publicado no site da MTV. De tempos em tempos jovens 
anônimos se revezam na participação. Eles escrevem no site falando de si mesmos, dos amigos, do trabalho. Publicam fotos, fazem playlists com suas músicas e artistas preferidos, indicam links e recebem comentários dos visitantes do site, que podem indicar outros links.

No programa que vai ao ar na televisão, a janela principal mostra os videoclipes que estão no playlist de cada participante. Sobre estas imagens abrem-se frames que vão "carregando" informações em formato de video de baixa definição, como os videos que são propagados na internet. Nestes, os participantes dão depoimentos, amigos e membros da família fazem comentários, outros frames com textos se abrem dando detalhes sobre o videoclipe que está passando, ou com comentários deixados pela audiência no site. A tela da televisão exibe várias partes do infoespaço, com imagens, textos, sons que se sobrepõem, tudo de maneira simultânea. A estética do programa é a mesma estética característica da navegação na web.

No blog temos um hipertexto que, segundo Lévy (2001: 43), é diferente de outros tipos de textos, porque nele todo ato de leitura se transforma num ato de escrita. Toda vez que navegamos por um hipertexto criamos nosso próprio caminho a partir das escolhas que fazemos entre os vários textos potenciais.

$\mathrm{O}$ "Vidalog" é um texto tradicional que imita a estética de um hipertexto, ele está pronto, o diretor do programa é quem vai construí-lo partindo do conteúdo do blog; vai navegar pelo blog, ler, interpretar, selecionar, editar e ainda acrescentar videos feitos por ele. Os espectadores assistem ao programa e participam em tempo presente, formam suas opiniões, mas não podem modificar este texto. Portanto, ao contrário do $b \log$, o programa na televisão não é um texto coletivo, embora já traga embutidas percepções mais elevadas de participação em profundidade e de navegação pelo espaço virtual do computador. Além disso, demonstra que a televisão, com seu aspecto devorador de outras linguagens, já está incorporando a estética e a linguagem da internet.

\section{Considerações finais}

Todos os programas apresentados neste trabalho são metaformas. São textos cujas mensagens estão além do seu tempo, esperando a chegada de um meio que possibilite a real construção de uma linguagem interativa. Trazem embutidos dentro de seus formatos, percepções que já circulam pela sociedade de maneira quase invisível, modificando hábitos, costumes e relacionamentos.

Como explica Johnson de maneira romântica, as metaformas são como parasitas:

Flutuam por nossas telas de televisão como sugestões e insinuações, um vislumbre do futuro escondido nas roupas gastas e restritivas do passado, como um corpo cubista ataviado com espartilhos e renda. São fantasmas de tecnologias que estão por vir (2001: 31).
A televisão, enquanto tecnologia eletrônica, precisa de uma grande quantidade de informação e conteúdo para preencher suas infindáveis horas de programação e parece não ter perdido tempo em tomar para si, a linguagem, a estética e as novas percepções do computador e da internet.

Como resultado destas experimentações - dentro da televisão e nos outros meios de comunicação teremos num futuro não muito distante a configuração de uma linguagem que será fruto da conexão do nosso sistema nervoso central com as possibilidades da tecnologia da TV digital interativa.

A tecnologia da escrita não chegou ao estágio no qual a conhecemos hoje de repente. Gutenberg inventou a prensa tipográfica em 1455, mas não o livro. Os livros impressos antes de 1501 são chamados incunábulos, expressão em latim que era atribuída às faixas com as quais os bebês eram enrolados. Eram chamados assim porque sua tecnologia ainda estava na infância. Mais de 50 anos foram necessários para experimentações, que resultaram em algumas convenções como a numeração de páginas, o uso de parágrafos, páginas de rosto, divisão por capítulos, prefácios, etc (Murray, 2001: 41).

A televisão, como a conhecemos hoje, pode ser considerada uma tecnologia da infância de uma nova linguagem ligada às tecnologias multimídias de comunicação, que incluirá imagens videográficas, textos escritos, sons e interatividade; o "incunábulo" de um meio expressivo que está por vir.

A construção de parâmetros e convenções para este meio expressivo emergente deverá estar relacionada aos usos que está nova geração, hoje espectadora da MTV Brasil, dará para estas tecnologias de comunicação e pelas experiências desenvolvidas pelas grandes empresas de comunicação na busca de atender as necessidades, expectativas e percepções do mundo cotidiano destes espectadores. mamecos

\section{NOTAS}

1. Tal perfil do jovem da sociedade contemporânea é apresentado na reportagem "A cabeça no mundo, os pés em casa" na Revista Veja Edição Especial Jovens n.32 ano 37 de junho de 2004, nas páginas 28-32.

2. Gumbrecht parte da teoria de Hjelmslev para traçar um cenário para o campo não-hermenêuti$\mathrm{co}$, assumindo que este pensamento é pertencente ao campo hermenêutico.

3. Que concentra as especificidades materiais do significante.

4. Campo que concentra as análises tradicionais da interpretação focando-se nas formas e estruturas articuladoras da substância do conteúdo. 
5. Espaço onde uma materialidade ainda não está formada.

6. Espaço denominado pelo imaginário, onde não há binarismos, onde ainda não temos formas do conteúdo, pois estamos num momento anterior ao que denominamos "sentido".

7. Esta teoria foi desenvolvida por Humberto Maturana e Francisco Varela e pressupõe sempre a presença de dois sistemas em processo de interação ou acoplagem na qual as substâncias se combinam resultando em outras formas. Numa acoplagem de primeiro nível os resultados são previsíveis e finitos, numa acoplagem de segundo nível as possibilidades de combinação são infinitas e imprevisíveis, constantemente criando formas diferentes e inesperadas. É sobre o conceito de acoplagens de segundo nível que Gumbrecht (1998, p. 149) vai se apoiar para estruturar o viés da materialidade.

8. Gumbrecht assume que tal teorema por ele proposto ainda está incompleto, mas acredita que trabalhando o conceito de acoplagem podemos desenvolver uma teorização da pergunta-chave do panorama intelectual contemporâneo: como, de um estado de formação, atinge-se o de representação. (1998: 150).

9. A Gestalt é uma Escola de Psicologia Experimental que busca explicar como o homem percebe visualmente as formas. A percepção de vários elementos como um todo pode ser conseguida com a aplicação das leis da Gestalt, baseadas sempre nas formas mais simples e, consequentemente, mais fortes.

10. McLuhan explica o conceito de "participação em profundidade" e descreve as diferenças entre as percepções referentes às tecnologias mecânicas e eletrônicas em entrevista concedida a Frank Kermode, em 24 de janeiro de 1965, no programa "Monitor" da British Broadcasting Corporation. Nesta entrevista ele também explica que os homens pré-letrados não usam os olhos da mesma maneira com que os homens letrados aprenderam a usar os seus, portanto as imagens são "vistas" de diferentes formas dependendo de como treinamos as nossas percepções.

11. Este artigo é fruto do trabalho de dissertação de mestrado em comunicação da UNIP no qual o corpo de pesquisa é composto pela grade de programação da emissora durante o período de 01/01/06 até 30/04/06.

\section{REFERÊNCIAS}

BALOGH, Ana Maria. O discurso ficcional na tv: Sedução e Sonho em Doses Homeopáticas. São Paulo: Editora da Universidade de São Paulo, 2002, 23-29.

CASTELLS, Manuel. A cultura da virtualidade Real: a integração da comunicação eletrônica, of fim da audiência em massa e o surgimento das redes interativas. In Sociedade da Informação. São Paulo: Paz e Terra, 1999.

FELINTO, Erick; ANDRADE, Vinicius. A vida dos objetos. in Revista Contemporânea, vol.3.n.1,75-94.

\section{GUMBRECHT, Hans Ulrich. O Campo Não-} Hermenêutico ou a Materialidade da Comunicação. In Corpo e Forma. Rio de Janeiro: Eduerj, 1998.

JOHNSON, Steven. Cultura da interface: como o computador transforma nossa maneira de criar e comunicar. Rio de Janeiro: Jorge Zahar, 2001, 15-35.

LÉVY, Pierre. A virtualização do texto. In O que é Virtual? São Paulo: Editora 34, 2001.

LUSVARGH, Luiza Cristina. A MTV Brasil - a padronização da cultura na mídia eletrônica. Dissertação de mestrado apresentada à ECAEscola de Comunicação e Artes da Universidade de São Paulo. São Paulo: 2002.

MAFFESOLI, Michel. O conhecimento Comum, compendio de sociologia compreensiva. São Paulo: Ed. Brasiliense, 1998.

McLUHAN, Marshall. Os meios de Comunicação como extensões do homem. São Paulo: Cultrix, 1971.

- McLuhan por McLuhan: conferências e entrevistas. (org) Stephanie McLuhan e David Staines. Rio de Janeiro: Ediouro, 2005.

MONTEZ, Carlos; BECKER, Valdecir. TV digital interativa: conceitos, desafios e perspectivas para o Brasil. Florianópolis: Ed. da UFSC -2. edição revista e ampliada, 2005.

MURRAY, Janet H. Hamlet no Holodeck: o futuro da narrativa no ciberespaço. São Paulo: Itaú Cultural: Unesp, 2003, 73-75.

NATÁRIO, Eduardo S; WAJNMAN Solange. O controle remoto e a interatividade na televisão. In www.compos.com.br/e-compos. abril de 2006. Ultimo acesso 17/11/06. 